\title{
Cardiovascular diseases in Brazil: premature mortality, risk factors and priorities for action. Comments on the preliminary results from the Brazilian National Health Survey (PNS), 2013
}

\author{
Doenças cardiovasculares no Brasil: mortalidade prematura, fatores de risco \\ e prioridades de ação. Comentários sobre os resultados preliminares da \\ Pesquisa Nacional de Saúde (PNS), 2013
}

Paulo Andrade Lotufo'

'MD, DrPH. Titular Professor, Discipline of Internal Medicine, Faculdade de Medicina da Universidade de São Paulo (FMUSP), São Paulo, Brazil.

\section{SITUATION \#1: UNDERSTANDING CARDIOVASCULAR EPIDEMIOLOGY IN BRAZIL}

1. Mortality: Cardiovascular diseases - coronary heart disease (CHD) and stroke - are the main cause of death worldwide. ${ }^{1}$ Over recent decades, Brazil has witnessed a decline in mortality rates due to CHD and stroke. ${ }^{2,3}$ However, in 2012, these diseases were the first and the third commonest causes of premature death nationwide, respectively. ${ }^{1}$ Table $\mathbf{1}^{4-6}$ shows the proportion of deaths among individuals under the age of 70 years due to all cardiovascular diseases, $\mathrm{CHD}$ alone and the combination of stroke and hypertensive disorders, according to sex and race, in Brazil in 2012. The proportion of premature deaths due to $\mathrm{CHD}$ is higher than the proportion due to stroke for both sexes and all races. Men die due to all cardiovascular events earlier than women. According to skin color/race, the chance of death under the age of 70 years is highest for black individuals, followed by mixed race and white people. To understand this picture better, so as to enable effective intervention, more information concerning morbidity and risk factors is necessary.

2. Incidence and case-fatality: The morbidity due to cardiovascular diseases can be ascertained by determining the incidence and case-fatality rates. Population-based incidence rates have been obtained from studies limited to a single city. ${ }^{7}$ Case-fatality rates are easier to obtain from the organized hospital-based registries that have been created in Brazil..$^{8-10}$ These registries are helpful in determining the levels of pre-hospital care, compliance with guidelines among the medical team and, especially, quality of procedures such as thrombolytic therapy, angioplasty and coronary revascularization. In addition, data on the adherence among

Table 1. Numbers and proportions of deaths among individuals under the age of 70 years due to all cardiovascular diseases, stroke and hypertension and coronary heart disease (CHD), in comparison with the events that occurred at all ages

\begin{tabular}{lcccccc} 
& \multicolumn{2}{c}{ All cardiovascular diseases } & \multicolumn{2}{c}{ Stroke and hypertension } & \multicolumn{3}{c}{ CHD } \\
\cline { 2 - 7 } & $\mathbf{N}$ & $\%$ & $\mathbf{N}$ & $\%$ & $\mathbf{N}$ & $\%$ \\
All individuals & 135,893 & 40.8 & 52,558 & 36.1 & 49,625 & 47.5 \\
Sex & & & & & & \\
$\quad$ Male & 82,434 & 47.3 & 29,477 & 41.1 & 33,087 & 54.5 \\
$\quad$ Female & 53,449 & 33.7 & 23,074 & 31.3 & 16,535 & 37.9 \\
Race & & & & & & \\
$\quad$ White & 64,102 & 36.0 & 22,496 & 31.2 & 25,523 & 43.3 \\
Mixed & 50,483 & 46.6 & 20,550 & 40.6 & 17,531 & 53.7 \\
$\quad$ Black & 14,184 & 50.1 & 6,414 & 45.8 & 4,307 & 56.9 \\
$\quad$ Asian & 511 & 26.1 & 207 & 24.5 & 190 & 31.2 \\
$\quad$ Amerindian & 198 & 38.2 & 91 & 33.7 & 59 & 44.4 \\
\hline
\end{tabular}


patients who suffered cardiovascular events, regarding the advice that they were given about diet, exercise and use of medicines, can be obtained. In summary, hospital-based registries are important for improving the quality of medical care, but they do not help to create preventive programs. Strategies for preventive action depend on obtaining a certain minimum knowledge regarding the prevalence of morbidity and risk factors at the population level.

3. Prevalence: Determining the prevalence of cardiovascular risk factors is not an easy task in a country that is as large as Brazil. However, during 2013, the Ministry of Health carried out the first national representative survey addressing health conditions, morbidity and risk factors among a sample of Brazilians over the age of 18 years, called "Pesquisa Nacional de Saúde" (PNS), or the Brazilian National Health Survey. The preliminary results were released in December 2014, including new information about hypertension, dyslipidemia, diabetes and smoking habits. ${ }^{11}$ Table 2 summarizes the main results, which will be detailed below.

\section{SITUATION \#2: CARDIOVASCULAR RISK FACTORS IN THE NATIONAL HEALTH SURVEY}

1. Hypertension: This is the most significant risk factor for morbidity and mortality due to stroke in Brazil, despite the reduction in the risk of death. The proportion of individuals who have never had a blood pressure measurement made is insignificant. The prevalence of medical diagnoses among individuals over the age of 18 years is approximately the same

Table 2. Description of risk factors evaluated in the first Brazilian National Health Survey, 2013

\begin{tabular}{lccc} 
Risk factor & Total & Men & Women \\
Hypertension & & & \\
$\quad$ Never had blood pressure measured & 3.0 & 4.3 & 1.7 \\
Medical diagnosis & 21.4 & 18.3 & 24.2 \\
Using medications & 81.4 & 74.5 & 84.6 \\
$\quad$ Medical visit last year & 69.7 & 65.6 & 72.4 \\
$\quad$ Free access to medicines & 35.9 & 31.8 & 36.6 \\
\hline Diabetes & & & \\
$\quad$ Never had blood glucose measured & 11.5 & 14.9 & 7.8 \\
$\quad$ Medical diagnosis & 6.2 & 5.4 & 7.0 \\
$\quad$ Using medications & 80.2 & 81.2 & 79.6 \\
$\quad$ Medical visit last year & 73.2 & 68.1 & 70.2 \\
$\quad$ Free access to medicines & 57.4 & 54.9 & 55.6 \\
\hline High cholesterol & & & \\
$\quad$ Never had cholesterol measured & 14.3 & 18.2 & 10.0 \\
$\quad$ Medical diagnosis & 12.5 & 9.7 & 14.4 \\
\hline Smoking & & & \\
$\quad$ Current smoker & 14.7 & 18.9 & 11.0 \\
$\quad$ Trying or tried to quit & 51.1 & 47.9 & 55.9 \\
Seeking medical support for quitting & 8.8 & 6.2 & 9.7
\end{tabular}

as observed in earlier localized surveys in Brazil. However, the most important finding is that among people who selfdeclare as "hypertensive", $80 \%$ are taking medications. It was found that one-third of the people with high blood pressure had free access to antihypertensive drugs. Men and women did not have the same behavior regarding medical visits and use of medicines.

2. Diabetes: Plasma or blood glucose measurements were made at least once for approximately $90 \%$ of the participants. A medical diagnosis of diabetes was made in $6.2 \%$. If it is accepted that half of the people with diabetes do not know about this situation until they are tested, ${ }^{12}$ the presumptive prevalence of $12 \%$ thus obtained is relatively close to that of other recent surveys in Brazil. ${ }^{13,14}$ Likewise, $80 \%$ of the individuals with hypertension were underusing medicines. In contrast, the proportion of diabetics receiving drugs free of charge was significantly different from the proportion of individuals with hypertension.

3. Dyslipidemia: The participants were asked about cholesterol and/or triglyceride measurements, and $85 \%$ confirmed that they had been tested for dyslipidemia during their lifetimes. A medical diagnosis of dyslipidemia had been made in the cases of $14.3 \%$ of the participants, with a significant difference between the sexes.

4. Smoking: The survey identified an astonishing prevalence of current smoking: $18.9 \%$ among men and 11\% among women. Almost half of them were trying to quit, but fewer than $10 \%$ had sought medical advice and support.

\section{COMMENT \# 1: THE NATIONAL HEALTH SYSTEM IS ALSO WORKING TOWARDS A "HEALTHY HEART"}

The general view concerning cardiovascular risk factors is optimistic. The National Health System that was created in 1988 has implemented primary care and family health programs and this, together with better risk management within the private sector, is providing greater access for diagnosing and treating cardiovascular risk factors. This is having an impact on cardiovascular disease rates. ${ }^{15,16}$ Free-of-charge access to medicines for hypertension and diabetes, which was launched by the National Health System in 2007, is showing good results despite controversy regarding the portfolio of antihypertensive medicines. ${ }^{17}$

Another interesting point is that the "delayed cardiovascular epidemiological transition in Brazil", i.e. the preponderance of mortality due to stroke over mortality due to $\mathrm{CHD}$, has vanished. ${ }^{18}$ On the other hand, the racial gap regarding cardiovascular mortality is not exclusive to hypertension and stroke. ${ }^{19}$ As shown in Table 1, deaths due to CHD are more premature among blacks than among whites. 


\section{COMMENT \#2: THERE HAS BEEN AN IMPRESSIVE PUBLIC-HEALTH VICTORY IN RELATION TO CURBING THE SMOKING EPIDEMIC}

The most import finding is the lower prevalence of current smokers compared with three decades ago. ${ }^{20}$ This has certainly had an impact on the reduction of cardiovascular and respiratory mortality in Brazil. One important point to consider in this regard is that the effects of laws to restrict and advertising to restrain the smoking habit are probably at the limit of their efficacy. The reason is that most of these $15 \%$ who continue to smoke are in fact addicted to nicotine. This implies that there is a need for organized actions within primary care settings, such as psychological support and free availability of effective drugs for supporting nicotine withdrawal. ${ }^{21,22}$

\section{COMMENT \#3: DYSLIPIDEMIA NEEDS TO BE THE PRIORITY FOR PRIMARY CARE PROVIDERS}

The priorities of the program for controlling hypertension and diabetes were established 15 years ago. However, as indicated in Table 1 , the proportion of premature CHD in Brazil is higher than that of stroke. Dyslipidemia has been recognized as the most important risk factor for CHD since the time of the first results from the Framingham Heart Study. ${ }^{23}$ In addition, the impact of lipid-lowering agents has been very well documented in randomized clinical trials relating to primary and secondary prevention. ${ }^{24}$ The recent and controversial guidelines from the American Heart Association/ American College of Cardiology recommend that statins should be prescribed. Moreover, they recommend that instead of considering cholesterol levels in isolation, the overall cardiovascular risk should be assessed by adding information about blood pressure, diabetes and smoking to the cholesterol data. ${ }^{25}$ In contrast to two decades ago, when statins first came onto the market, statins today are generic drugs with relatively low cost and they need to be included in the free-of-charge access program for cardiovascular prevention.

In conclusion, the scientific community, public and private healthcare administrators and the entire National Health System need to combine their efforts to combat the burden of heart diseases. The first Brazilian National Health Survey will be a very useful tool for cardiology prevention in this country.

\section{REFERENCES}

1. GBD 2013 Mortality and Causes of Death Collaborators. Global, regional, and national age-sex specific all-cause and cause-specific mortality for 240 causes of death, 1990-2013: a systematic analysis for the Global Burden of Disease Study 2013. Lancet. 2015;385(9963):117-71.

2. Lotufo PA. Why has the rise in obesity not reversed the decline in cardiovascular mortality? Cardiometabolic death rate trends in Brazil (1980-2011). Sao Paulo Med J. 2015;133(1):1-3.
3. Lotufo PA, Goulart AC, Fernandes TG, Benseñor IM. A reappraisal of stroke mortality trends in Brazil (1979-2009). Int J Stroke. 2013;8(3):155-63.

4. World Health Organization. Hypertensive diseases. In: World Health Organization. International Classification of Diseases (ICD). $10^{\text {th }}$ ed. Available from: http://apps.who.int/classifications/icd10/ browse/2015/en\#/I10-115. Accessed in 2015 (Mar 10).

5. World Health Organization. Ischaemic heart diseases. In: World Health Organization. International Classification of Diseases (ICD). $10^{\text {th }}$ ed. Available from: http://apps.who.int/classifications/icd10/ browse/2015/en\#/I20-125. Accessed in 2015 (Mar 10).

6. World Health Organization. Cerebrovascular diseases. In: World Health Organization. International Classification of Diseases (ICD). $10^{\text {th }}$ ed. Available from: http://apps.who.int/classifications/icd10/ browse/2015/en\#/160-169. Accessed in 2015 (Mar 10).

7. McGovern PG, Jacobs DR Jr, Shahar E, et al. Trends in acute coronary heart disease mortality, morbidity, and medical care from 1985 through 1997: the Minnesota heart survey. Circulation. 2001;104(1):19-24.

8. Goulart AC, Santos IS, SitnikD, et al. Design and baseline characteristics of a coronary heart disease prospective cohort: two-year experience from the strategy of registry of acute coronary syndrome study (ERICO study). Clinics (Sao Paulo). 2013;68(3):431-4.

9. Nicolau JC, Franken M, Lotufo PA, et al. Utilização de terapêuticas comprovadamente úteis no tratamento da coronariopatia aguda: comparação entre diferentes regiões brasileiras. Análise do Registro Brasileiro de Síndromes Coronarianas Agudas (BRACE - Brazilian Registry on Acute Coronary Syndromes) [Use of demonstrably effective therapies in the treatment of acute coronary syndromes: comparison between different Brazilian regions. Analysis of the Brazilian Registry on Acute Coronary Syndromes (BRACE)]. Arq Bras Cardiol. 2012;98(4):282-9.

10. Piva e Mattos LA, Berwanger O, Santos ES, et al. Desfechos clínicos aos 30 dias do registro brasileiro das síndromes coronárias agudas (ACCEPT) [Clinical outcomes at 30 days in the Brazilian Registry of Acute Coronary Syndromes (ACCEPT)]. Arq Bras Cardiol. 2013;100(1):6-13.

11. Brasil. Instituto Brasileiro de Geografia e Estatística. Pesquisa Nacional de Saúde 2013. Percepção do estado de saúde, estilos de vida e doenças crônicas. Brasil, Grandes Regiões e Unidades da Federação. Available from: http://www.ibge.gov.br/home/estatistica/populacao/ pns/2013/default.shtm. Accessed in 2015 (Mar 10).

12. Schmidt MI, Hoffmann JF, Diniz MFS, et al. High prevalence of diabetes and intermediate hyperglycemia - The Brazilian Longitudinal Study of Adult Health (ELSA-Brasil). Diabetology \& Metabolic Syndrome. 2014;6:123. Available from: http://www.dmsjournal.com/content/ pdf/1758-5996-6-123.pdf. Accessed in 2015 (Mar 10).

13. Oliveira JE, Milech A, Franco $L$. The prevalence of diabetes in Rio de Janeiro, Brazil. The Cooperative Group for the Study of Diabetes Prevalence in Rio de Janeiro. Diabetes Care. 1996;19(6):663-6. 
14. Torquato MT, Montenegro Júnior RM, Viana LA, et al. Prevalence of diabetes mellitus and impaired glucose tolerance in the urban population aged 30-69 years in Ribeirão Preto (São Paulo), Brazil. Sao Paulo Med J. 2003;121(6):224-30.

15. Rasella D, Harhay MO, Pamponet ML, Aquino R, Barreto ML. Impact of primary health care on mortality from heart and cerebrovascular diseases in Brazil: a nationwide analysis of longitudinal data. BMJ. 2014;349:94014

16. Brasil. Ministério da Saúde. Plano de ações estratégicas para o enfrentamento das doenças crônicas não transmissíveis (DCNT) no Brasil 2011-2022. Brasília: Ministério da Saúde; 2011. Available from: http://bvsms.saude.gov.br/bvs/publicacoes/plano_acoes_enfrent_ dcnt_2011.pdf. Accessed in 2015 (Mar 10).

17. Lotufo PA, Pereira AC, Vasconcellos PS, et al. Resistant hypertension: risk factors, subclinical atherosclerosis, and comorbidities among adults - the Brazilian Longitudinal Study of Adult Health (ELSA-Brasil). J Clin Hypertens (Greenwich). 2015;17(1):74-80.

18. Lotufo PA, Benseñor IM. Stroke mortality in Brazil: one example of delayed epidemiological cardiovascular transition. Int J Stroke. 2009:4(1):40-1.

19. Lotufo PA, Benseñor IJ. Raça e mortalidade cerebrovascular no Brasil [Race and stroke mortality in Brazil]. Rev Saude Publica. 2013;47(6):1201-4.

20. Rego RA, Berardo FAN, Rodrigues SSF, et al. Fatores de risco para doenças crônicas não-transmissíveis: inquérito domiciliar no Município de São Paulo, SP (Brasil). Metodologia e resultados preliminares [Risk factors for non-communicable chronic diseases: a domiciliary survey in the Municipality of São Paulo, (Brazil). Methodology and preliminary results]. Rev Saude Publica. 1990;24(4):277-85

21. Mottillo $S$, Filion KB, Bélisle $P$, et al. Behavioural interventions for smoking cessation: a meta-analysis of randomized controlled trials. Eur Heart J. 2009;30(6):718-30

22. Eisenberg MJ, Filion KB, Yavin D, et al. Pharmacotherapies for smoking cessation: a meta-analysis of randomized controlled trials. CMAJ. 2008;179(2):135-44.

23. Dawber TR, Kannel WB, Revotskie N, et al. Some factors associated with the development of coronary heart disease: six years' follow-up experience in the Framingham study. Am J Public Health Nations Health. 1959;49:1349-56.

24. McConnachie A, Walker A, Robertson M, et al. Long-term impact on healthcare resource utilization of statin treatment, and its cost effectiveness in the primary prevention of cardiovascular disease: a record linkage study. Eur Heart J. 2014;35(5):290-8.

25. Stone NJ, Robinson JG, Lichtenstein AH, et al. 2013 ACC/AHA guideline on the treatment of blood cholesterol to reduce atherosclerotic cardiovascular risk in adults: a report of the American College of Cardiology/American Heart Association Task Force on Practice Guidelines. J Am Coll Cardiol. 2014;63(25 Pt B):2889-934.

\section{Sources of funding: None}

Conflict of interest: None

Date of first submission: January 25, 2015

Last received: January 25, 2015

Accepted: January 25, 2015

\section{Address for correspondence:}

Paulo Andrade Lotufo

Centro de Pesquisa Clínica e Epidemiológica, Hospital Universitário, Universidade de São Paulo

Av. Prof. Lineu Prestes, 2.565

Butantã — São Paulo (SP) - Brasil

Tel. (+55 11) 3091-9300

E-mail:palotufo@hu.usp.br 